\title{
Effects of nicotine, its metabolites and tobacco extracts on human platelet function in vitro
}

\author{
Liza Ljungberg, Karin Persson, Andreas Eriksson, Henrik Green and Per Whiss
}

\section{Linköping University Post Print}

\section{Tweet}

N.B.: When citing this work, cite the original article.

Original Publication:

Liza Ljungberg, Karin Persson, Andreas Eriksson, Henrik Green and Per Whiss, Effects of nicotine, its metabolites and tobacco extracts on human platelet function in vitro, 2013, Toxicology in Vitro, (27), 2, 932-938.

http://dx.doi.org/10.1016/j.tiv.2013.01.004

Copyright: Elsevier http://www.elsevier.com/

Postprint available at: Linköping University Electronic Press http://urn.kb.se/resolve?urn=urn:nbn:se:liu:diva-91549 


\section{EFFECTS OF NICOTINE, ITS METABOLITES AND TOBACCO EXTRACTS ON HUMAN PLATELET FUNCTION IN VITRO}

Liza U Ljungberg, $\mathrm{PhD}^{\mathrm{a}, \mathrm{b}}$, Karin Persson, $\mathrm{PhD}^{\mathrm{b}}$, Andreas C Eriksson, $\mathrm{PhD}^{\mathrm{b}}$, Henrik Green, $\mathrm{PhD}^{\mathrm{b}, \mathrm{c}}$, Per A Whiss, $\mathrm{PhD}^{\mathrm{b}}$

${ }^{\text {a }}$ Division of Cardiovascular Medicine, Department of Medical and Health Sciences, Faculty of Health Sciences, Linköping University, SE-581 85 Linköping, Sweden

${ }^{\mathrm{b}}$ Division of Drug Research, Pharmacology, Department of Medical and Health Sciences, Faculty of Health Sciences, Linköping University, SE-581 85 Linköping, Sweden

${ }^{\mathrm{c}}$ Science for Life Laboratory, School of Biotechnology, Division of Gene Technology, Royal Institute of Technology, SE-171 65 Solna, Sweden

\section{Correspondence:}

Liza U Ljungberg, Division of Cardiovascular Medicine, Department of Medical and Health Sciences, Faculty of Health Sciences, Linköping University, SE-58185 Linköping, Sweden Email: liza.ljungberg@liu.se, liza.ljungberg@gmail.com

Telephone: +46101037476

Fax: +4613149106

ABBREVIATIONS: ADP: adenosine 5-diphosphate, ELISA: enzyme-linked immunosorbent assay, HPLC: high-performance liquid chromatography, IBMX: 3-Isobutyl-1-methylxanthine, ODQ: 1,2,4-Oxadiazolo[4,3-a]quinoxalin-1-one, PBS: phosphate-buffered saline

\section{HIGHLIGHTS}

- Tobacco extracts inhibit platelet adhesion to proteins surfaces.

- This effect is independent of nitric oxide and a platelet nicotine receptor.

- Nicotine and nicotine metabolites have limited effect on platelet activity in vitro. 


\begin{abstract}
Cigarette smoking is a leading cause of cardiovascular disease. The cardiovascular effects of smoking are probably multifactorial, including effects on platelets. Previous reports investigating the effects of nicotine and tobacco on platelet function are inconsistent. The present study investigated in vitro effects of nicotine, its major metabolites, tobacco extracts and extract of tobacco-free snuff on human platelets.

None of the metabolites cotinine, cotinine- $\mathrm{N}$-oxide, nicotine- $1^{\prime}-\mathrm{N}$-oxide or trans-3'hydroxycotinine $(0.1-10 \mu \mathrm{M})$ affected platelet aggregation or P-selectin expression. Nicotine $(10 \mu \mathrm{M})$ weakly increased platelet aggregation, whereas trans-3'-hydroxycotinine $(0.1 \mu \mathrm{M})$ and nicotine-1'-N-oxide (1-10 $\mu \mathrm{M})$ weakly inhibited adhesion to fibrinogen. To elucidate the influence of other tobacco compounds, we investigated the impact of moist tobacco and smoke extracts on platelet function. Filtered extracts of oral snuff, cigarette smoke and tobacco free snuff inhibited platelet adhesion concentration-dependently. The inhibitory effects of tobacco extracts on platelet adhesion were independent of nicotine content and the nitric-oxide-pathway and not mediated through a platelet-nicotine-receptor.

Taken together, tobacco extracts inhibit platelet activation during short-term in vitro challenge. As only limited effects of nicotine and nicotine metabolites were seen, the tobaccoinduced platelet inhibition are likely induced by other compounds present in tobacco and tobacco free snuff.
\end{abstract}

KEYWORDS: cigarette smoke, moist tobacco, nicotine metabolite, platelet adhesion, platelet aggregation, snuff 


\section{INTRODUCTION}

There is no doubt about the harmful effects of smoking on the cardiovascular system. The exact mechanisms by which smoking induces cardiovascular disease are not entirely known, but are most likely multifactorial. The effects of cigarette smoke on platelets have been investigated in numerous studies, but the results are somewhat contradictory. Cigarette smoke has been shown to activate platelets, which results in increased clot strength ex vivo (Barua et al., 2010) and increased P-selectin expression (Lupia et al., 2010). In addition, smokers show increased spontaneous aggregation ex vivo (Fusegawa et al., 1999) and smoking has been found to increase agonist induced platelet aggregation in vitro (Hung et al., 1995). However, there are also studies showing that platelet aggregation after in vitro activation, as well as in vitro bleeding time is either unchanged or decreased in smokers compared to non-smokers (Brockmann et al., 2001; Nair et al., 2001). Smokeless oral tobacco is probably less harmful than cigarettes, although long-term use of oral snuff, has been shown to increase the risk of fatal myocardial infarction (Hergens et al., 2007). Studies on the influence of oral snuff on platelet function are scarce, but one study showed unchanged urinary levels of a metabolite of the platelet activation marker thromboxane $A_{2}$, after use of oral snuff (Wennmalm et al., 1991).

Tobacco products are complex mixtures of compounds, containing not only nicotine, but also a numerous of other pharmacologically active substances (Benowitz \& Gourlay 1997).

Nicotine affects the cardiovascular system in many ways, some mechanisms being well characterized. By activating the sympathetic nervous system, nicotine induces increased heart rate and myocardial contraction, vasoconstriction in the skin and adrenal and neural release of catecholamines (Benowitz 1996). Nicotine can also affect lipid metabolism (Cluette-Brown et al., 1986), accelerate the development of atherosclerosis (Strohschneider et al., 1994) and induce endothelial dysfunction (Chalon et al., 2000). After entering the circulation, nicotine is subjected to extensive metabolism, resulting in a number of major and minor metabolites. On average, $70-80 \%$ of the nicotine is metabolized to cotinine, about $4 \%$ is converted to nicotine$1^{\prime}$-N-oxide and $0.4 \%$ to nornicotine (Benowitz \& Jacob 1994). Cotinine is further metabolized to cotinine-N-oxide and trans-3'-hydroxycotinine, among others (Benowitz et al., 1994). Trans-3'-hydroxycotinine is the most abundant metabolite in urine, accounting for on average $38 \%$ of the metabolites (Benowitz et al., 1994). As most of the metabolites have a considerably longer physiological half-life compared to nicotine, plasma concentrations of nicotine metabolites in tobacco users tend to accumulate throughout the day (Benowitz \& Jacob 1994; Benowitz \& Jacob 2001). Although the concentration of some of the nicotine metabolites in the blood is far higher than nicotine in tobacco users, few earlier studies have examined their effect on the cardiovascular system. Also, the direct effects of tobacco on platelets are relatively unknown. This study aimed to investigate the effects of nicotine, nicotine metabolites, tobacco extracts and tobacco free snuff on platelet function in vitro. 


\section{METHODS}

\section{Experimental design}

This study investigates the effect of tobacco on platelet function in vitro. Platelet adhesion, aggregation and P-selectin expression were evaluated after exposure to nicotine and its four most abundant metabolites in plasma. As tobacco products contains not only nicotine, but also a huge number of other substances, the effect of tobacco extracts (cigarette smoke and moist tobacco) on platelet adhesion were investigated. Moreover, a tobacco free substitute (choice apple) was also studied to investigate possible platelet effects of a plant extract that is used as an aid to stop smoking or using snuff. The impact of tobacco extracts on platelets was evaluated alone or in combination with known platelet activators (ADP and adrenaline). In addition, in order to study if the effect of the tobacco extracts were mediated via the nitric oxide (NO) system, which is known to inhibit platelets in vitro and in vivo, platelets were pretreated with 1) a phosphodiesterase inhibitor (IBMX) which inhibits degradation of cGMP resulting in augmented effect of NO, or 2) guanylyl cyclase inhibitor (ODQ) which inhibits the synthesis of cGMP and thus inhibits the effect of NO. Finally, platelets were pre-treated with the nicotine-receptor antagonist mecamylamine, to study if the effect of the extracts were mediated through the platelet nicotine receptor.

\section{Nicotine and Nicotine metabolites}

Nicotine and four of its most abundant liver metabolites, cotinine, nicotine-1'-N-oxide, cotinine-N-oxide and trans-3-hydroxycotinine, found in plasma were studied. Nicotine and cotinine were bought from Sigma-Aldrich (St Louis, MO, USA), while nicotine-1'-N-oxide, cotinine-N-oxide and trans-3'-hydroxycotinine were kind gifts from Dr Georg B. Neurath (Hamburg, Germany). All drugs were dissolved in distilled water, except for cotinine which was dissolved in ethanol and dilutions were made in $0.9 \% \mathrm{NaCl}$. Nicotine and nicotine metabolites were used in concentrations similar to those found in plasma from tobacco users (Benowitz et al., 1994).

\section{Preparation of tobacco extract}

Extract of oral snuff and tobacco free snuff was prepared using a protocol previously described (Petro et al., 2002), with a few modifications. Ten grams of oral (Ettan moist, Swedish Match, Stockholm, Sweden, and Copenhagen snuff fine cut, US Smokeless Tobacco Company, Richmond, VA, USA) or tobacco free snuff (Choice Apple, Nicofree, Trångsviken, Sweden) were mixed with $100 \mathrm{ml}$ phosphate-buffered saline (PBS) and incubated for $2 \mathrm{~h}$ at 37 ${ }^{\circ} \mathrm{C}$. The mixture was centrifuged for $10 \mathrm{~min}$ at $450 \times g$ followed by collection of the supernatant and re-centrifugation for $1 \mathrm{~h}$ at $13,000 \times g$. The suspension was filtered through a $0.2-\mu \mathrm{m}$ filter and $\mathrm{pH}$ was adjusted to 7.4 before being aliquoted and stored at $-70{ }^{\circ} \mathrm{C}$. The concentration of the filtered solution was considered as $100 \%$.

Cigarette smoke extract was prepared as described (Su et al., 1998), with few modifications. Smoke from two Camel filter cigarettes (R. J. Reynolds Tobacco Company, Winston-Salem, NC, USA) was drawn through $10 \mathrm{ml} \mathrm{PBS}$, pre-warmed to $37^{\circ} \mathrm{C}$, using water suction at a constant flow. All cigarettes were smoked to the same level (approximately $80 \%$ of the cigarette) and each cigarette was smoked for $5 \mathrm{~min} \pm 30 \mathrm{sec}$. The solution was sterilized using a $0.2 \mu \mathrm{m}$ filter and the obtained solution was considered as $100 \%$. Cigarette smoke extract was prepared $30 \mathrm{~min}$ prior to use. A broad concentration range was used for the tobacco extracts (0.001-10\%) to cover the plasma concentrations of the different constisuents in tobacco 
Analysis of nicotine content in tobacco extract

High-performance liquid chromatography (HPLC) was used to separate nicotine from other constituents and nicotine content was quantified using a UV detector. The system consisted of a P680 HPLC pump from Dionex (Sunnyvale, CA, USA), a Gina 50 autosampler and a photodiode array UV-detector UVD340U from Gynkotek (Germinger, Germany). The column was an X-bridge C18 $3 \mu \mathrm{m}, 3 \times 100 \mathrm{~mm}$ from Waters (Milford, MA, USA). Samples were separated using a mobile phase consisting of 5:95 (v/v) acetonitrile:ammonium formiate 10 $\mathrm{mM}, \mathrm{pH} 4.2$, at a flow rate of $500 \mu 1 / \mathrm{min}$. Each sample was injected into the HPLC system in a volume of $20 \mu \mathrm{l}$ and nicotine was detected at a wavelength of $260 \mathrm{~nm}$. The run time for each sample was 4 min and the retention time was $2.3 \mathrm{~min}$. A standard curve was constructed using $25,50,100$ and $250 \mu \mathrm{M}$ of nicotine. Cigarette smoke extract was diluted 1:1-1:5 in mobile phase, while oral snuff extract was diluted 1:25.

\section{Subjects}

The study conforms with the principles outlined in the Declaration of Helsinki, Finland 1964 and later revisions, and was approved by the Regional Ethical Review board in Linköping, Sweden. Blood was consecutively collected from healthy blood donors at the Blood Transfusion Centre, University Hospital, Linköping, Sweden. Blood donors were included only if they declared that they were non-tobacco users; had not used any antiplatelet drug such as aspirin for 2 weeks prior to the study; during the 3 previous months not suffered fever after visiting malaria region; suffered medical treatment-required conditions; been pregnant; used acupuncture, tattoo or piercing; been treated by dentist the previous 14 days; or had been vaccinated or suffered infection the previous month. In total, blood from 60 different blood donors was used.

\section{Platelet aggregation}

Venous blood was collected in silicone-coated vacutainer tubes with $3.8 \%$ trisodium citrate (blood/anticoagulant 9:1; BD Vacutainer®, Plymouth, UK). Platelet-rich plasma was obtained by centrifugation at $220 \times g$ for $20 \mathrm{~min}$; platelet poor plasma was prepared by further centrifugation at $1500 \times g$ for $10 \mathrm{~min}$. In vitro platelet aggregation induced by $10 \mu \mathrm{M}$ adenosine 5-diphosphate (ADP) was measured as previously described (Persson et al., 2000) in a Spectramax microplate reader (Molecular Devices, Sunnyvale, CA, USA).

\section{Static platelet adhesion}

Static platelet adhesion to albumin, collagen and fibrinogen was studied in 96-well microplates using a method previously described (Eriksson \& Whiss 2005). These surfaces were chosen since platelets use different adhesive mechanisms in order to adhere to different proteins. Platelet adhesion in this assay is known to be dependent on integrin $\alpha_{2} \beta_{1}$ for adhesion to collagen, while adhesion to fibrinogen and albumin occurs through integrin $\alpha_{\mathrm{IIb}} \beta_{3}$ (Eriksson \& Whiss 2009).

Venous blood was collected in 102 IU sodium heparin tubes (BD Vacutainer®). Platelet-rich plasma (PRP) was prepared and adhesion of platelets in plasma was investigated by incubating PRP in the presence of drugs/tobacco-extracts in the coated microplate wells for $1 \mathrm{~h}$ in room temperature. We also wanted to evaluate the effects of drugs/tobacco-extracts on platelet adhesion induced by the combination of a protein surface and a soluble platelet activator. In these experiments, the incubation was performed in the presence of added ADP or adrenaline (Mylan AB, Stockholm, Sweden). Furthermore, to investigate the possible influence from the nitric oxide system, PRP was incubated in the presence of either 3Isobutyl-1-methylxanthine (IBMX; Sigma-Aldrich) or 1,2,4-Oxadiazolo[4,3-a]quinoxalin-1- 
one (ODQ; Sigma-Aldrich). After incubation, the microplates were washed followed by detection of adhered platelets by an enzymatic/spectrophotometric procedure.

\section{Platelet P-selectin surface expression}

Blood was drawn into siliconized vacutainer tubes (BD Vacutainer®) containing 1:6 vol of acid citrate dextrose $(0.7 \mathrm{mM}$ citric acid, $9.3 \mathrm{mM}$ sodium citrate, and $13.6 \mathrm{mM}$ dextrose). Platelet P-selectin surface expression was analyzed by a previously described ELISA (Whiss et al., 1997). Briefly, isolated platelets in Hepes-buffered solution were incubated for $30 \mathrm{~min}$ with nicotine and nicotine metabolites prior to challenge with $10 \mu \mathrm{M}$ ADP, $0.1 \mathrm{U} / \mathrm{ml}$ thrombin (Sigma-Aldrich, St Louis, MO, USA) or solvent (Hepes-buffered solution) for 3 min at room temperature during a gentle rocking motion. After fixation, residual protein-binding sites in platelet-coated wells were blocked with PBS containing 5\% bovine serum albumin for $1 \mathrm{~h}$. This was followed by a washing procedure and incubation for $1 \mathrm{~h}$ with mouse monoclonal antibodies against P-selectin (clone 1E3, Dako A/S Glostrup, Denmark) and another $1 \mathrm{~h}$ incubation with secondary rabbit anti-mouse antibodies coupled to alkaline phosphatase (Dako A/S Glostrup, Denmark). Substrate hydrolysis by phosphatase was measured at $405 \mathrm{~nm}$ using a Spectramax microplate reader.

\section{Statistics}

Data are expressed as mean \pm SEM. Each $n$ represents independent experiments using platelets from different blood donors. The platelet adhesion, aggregation and $\mathrm{P}$-selectin experiments were performed in duplicates. Statistical significance was calculated using ONEway ANOVA for repeated measures followed by Dunnett's multiple comparison test. Pvalues $<0.05$ were considered statistically significant. Statistical analyses were carried out using GraphPad Prism 5 for Windows (version 5.04, GraphPad Software Inc, La Jolla, CA, USA). 


\section{RESULTS}

Effects of nicotine and its metabolites on platelet function

At $0.1-10 \mu \mathrm{M}$ none of the metabolites cotinine, cotinine-N-oxide, nicotine-1'-N-oxide or trans-3'-hydroxycotinine affected ADP-induced platelet aggregation. Only nicotine at $10 \mu \mathrm{M}$ caused a weak but significant increase in platelet aggregation (Fig 1).

Nicotine, cotinine and cotinine-N-oxide had no effect on platelet adhesion to the protein surfaces albumin, collagen or fibrinogen. Trans-3'-hydroxycotinine caused a weak inhibition on the fibrinogen surface exclusively at $0.1 \mu \mathrm{M}$ and nicotine-1'-N-oxide inhibited adhesion to fibrinogen at both 1.0 and $10 \mu \mathrm{M}$ (Fig 2).

To study the effects on an activation marker on platelets, nicotine and its metabolites were tested for their capacity to affect P-selectin surface expression on isolated platelets. None of the compounds caused any significant effect in this platelet assay (supplementary appendix A).

\section{Effect of tobacco extract on platelet adhesion}

The effect of oral snuff extract, cigarette smoke extract and extract of the tobacco free snuff Choice apple on static platelet adhesion to protein surfaces was studied. A reduction in platelet adhesion to collagen and fibrinogen was seen after treatment with $10 \%$ Ettan moist extract (Fig 3A). Copenhagen moist extract 10\% reduced platelet adhesion to collagen while adhesion to fibrinogen was reduced at 3\% and 10\% (Fig 3B). Extract of Camel cigarette smoke induced a significant decrease in adhesion to albumin and fibrinogen at all concentrations $(0.001-10 \%)$, while the adhesion to collagen was decreased at $3 \%$ and $10 \%$ (Fig 3C). Choice apple extract $10 \%$ reduced platelet adhesion to collagen while adhesion to fibrinogen was reduced at 3\% and 10\% (Fig 3D).

To further explore the inhibitory effects of tobacco extract on platelet adhesion, platelets were treated with tobacco extracts in combination with known platelet activators (ADP and adrenaline). Treatment with ADP and adrenaline alone increased the adhesion to albumin (Fig 4). Ettan moist induced a dose dependent reduction in adrenaline-induced adhesion to albumin, while ADP-induced platelet adhesion was inhibited at 10\% (Fig 4A).Camel extract $10 \%$ reduced both ADP and adrenaline-induced adhesion to albumin (Fig 4B). Ettan moist $10 \%$ and Camel extract inhibited adrenaline-induced adhesion to both collagen and fibrinogen, while no effect was seen on ADP-induced platelet adhesion (supplementary appendix B).

In order to study the cellular mechanisms behind the inhibitor effects of Ettan moist and camel extract on platelet adhesion, platelets were pre-treated with drugs that interfere with the nitric oxide system. Pre-incubation with IBMX (phosphodiesterase inhibitor) or ODQ (guanylyl cyclase inhibitor) did not affect the inhibitory effect of the tobacco extracts (data not shown).

To evaluate if the inhibitory effects of Ettan moist and Camel extract were mediated by nicotine, platelets were pre-treated with the nicotine-receptor inhibitor mechamylamine. Preincubation with mechamylamine did not affect the inhibitory effect of the tobacco extracts on platelet adhesion (data not shown). 
Analysis of nicotine content in tobacco extracts

The nicotine content in $100 \%$ oral snuff extract was $4.5 \mathrm{mM}$ and $6.5 \mathrm{mM}$ in Ettan and

Copenhagen snuff respectively, while the nicotine concentration in the cigarette smoke extract ranged from $300-643 \mu \mathrm{M}$. For the HPLC analysis, the between-day relative standard deviation (RSD) and precision were $\leq 8 \%$ and $98-101 \%$, respectively ( $n=4$ for 2 different

concentrations) and the within-day RSD and precision were $\leq 9 \%$ and $96-103 \%$, respectively ( $\mathrm{n}=4$ for 2 different concentrations). 


\section{DISCUSSION}

Studies investigating the effects of specific nicotine metabolites on the cardiovascular system are sparse, although several nicotine metabolites have been shown to be pharmacologically active (Crooks \& Dwoskin 1997; Ljungberg \& Persson 2008; Vainio et al., 2000). Previous findings from our lab show that nicotine and some of its metabolites increase activity and expression of angiotensin-converting enzyme in human endothelial cells (Ljungberg \& Persson 2008), however, no previous study has investigated the effects of the metabolites on platelet function. The present study showed that trans-3'-hydroxycotinine and nicotine-1'-Noxide induced a small but significant decrease in platelet adhesion to fibrinogen. As the plasma concentrations of some of the metabolites are far higher than nicotine (Benowitz \& Jacob 1994; Benowitz \& Jacob 2001), their impact on platelet function may be of physiological importance. In the present study, nicotine on the other hand had no effect on platelet adhesion to protein surfaces or platelet P-selectin expression, but induced a small but significantly increased ADP- induced platelet aggregation. Previous in vitro studies have shown both increased (Pfueller et al., 1988; Renaud et al., 1984), decreased (Becker et al., 1988; Rubenstein et al., 2004; Toivanen et al., 1986) and no effects (Nowak et al., 1996; Rubenstein et al., 2004) of nicotine on platelet activity. These diverse results are probably caused by the complex and diverse mechanism of nicotine, which is not readily degraded or removed from the receptor vicinity, leading to both agonistic and antagonistic properties in functional studies (Gahring \& Rogers 2005; Schedel et al., 2011). Since metabolites, such as cotinine, can inhibit cellular responses of nicotine and vice versa, this adds further difficulties to interpret the effects of nicotine (Vainio et al., 2000). The diverse mechanism of nicotine was observed in a previous study in our lab, which showed that nicotine infusion in tobacco users resulted in a rapid decrease in collagen-induced platelet aggregation which was restored after $2 \mathrm{~h}$ (Whiss et al., 2000). However, in the same subjects an up-regulation of platelet Pselectin expression was seen $2 \mathrm{~h}$ after nicotine infusion (Whiss et al., 2000), suggesting that both time and analysis method are essential in order to elucidate the effect of nicotine on platelet function. In addition, nicotine has been reported to increase the expression of the ADP-receptor P2Y12 in vitro in cultured human megakaryoblastic cells (Shanker et al., 2006), suggesting that smoking may result in production of transformed platelets. Furthermore, human platelets was recently shown to express functional nicotinic acetylcholine receptors (Schedel et al., 2011) and the authors suggested that agonist binding to this receptor induces $\mathrm{Ca}^{2+}$ influx and enhanced fibrinogen receptor activation but not platelet degranulation. As a further evidence of nicotine as both an activator and an inhibitor on platelet function, platelet aggregation was inhibited by a selective alfa7-nicotinic acetylcholine receptor agonist (Schedel et al., 2011).

As nicotine and nicotine metabolites only had limited and diverse effects on platelet activation in the present study, we hypothesized that other compounds in cigarette smoke could have greater impact on platelet function. Our findings showed that extract of cigarette smoke, oral snuff and tobacco free snuff inhibit platelet adhesion. The nicotine content in tobacco extracts did not appear to affect the level of platelet inhibition. The cigarette smoke extract, which contained the least nicotine of the tobacco extracts, was the extract that inhibited platelet adhesion at the lowest concentration. As nicotine and its metabolites caused such small effects per se, the effects of the tobacco extract are most likely mediated by other platelet inhibiting substances present in tobacco. Phenolic compounds, a class of antioxidants found in many plants (Kahkonen et al., 1999), and consequently also found in cigarette smoke (McGrath et al., 2009; Riveles et al., 2005), have previously been reported to inhibit platelets. The phenolic compounds rutin and quercetin have been reported to inhibit platelet aggregation (Gryglewski et al., 1987; Wright et al., 2010). Quercetin was also shown to reduce platelet 
release of serotonin (de Gasparo et al., 2000) and platelet surface expression of CD40L (Pignatelli et al., 2005). Importantly, the phenolic compounds quercetin and cathechin have also been reported to synergistically inhibit platelet aggregation and adhesion (Pignatelli et al., 2005). As these phenolic compounds are widely distributed in many plants it may explain the inhibitory effects after treatment with tobacco free snuff seen in the present study. Tobacco also contains salicylic acid (Perfetti \& Rodgman 2008), a well-known platelet inhibitor, which may contribute to the inhibitory effect of tobacco. In addition, raw tobacco as well as cigarette smoke contains nitric oxide (Perfetti \& Rodgman 2008) which is known to inhibit platelets. However, our study showed no effect on tobacco induced platelet inhibition when platelets were pre-treated with the phosphodiesterase inhibitor IBMX, which potentiates the effect of NO, and no effect of the guanylyl cyclase inhibitor ODQ, which abolish the effect of NO. This suggests that the inhibitory effect of tobacco extracts on platelet adhesion is not mediated by nitric oxide. Furthermore, carbon monoxide is present in tobacco smoke (Perfetti \& Rodgman 2008) and has been shown to inhibit platelets (Chlopicki et al., 2006). Carbon monoxide may well contribute to platelet inhibition after treatment with smoke extract, but cannot explain the effects of smokeless tobacco. The presence of different platelet inhibitors in tobacco makes it possible to hypothesize the occurrence of synergistic inhibitory interactions.

Numerous studies have revealed that smoking results in increased platelet activity as well as elevated risk for thrombosis (Barua et al., 2010; Davis \& Arnold 1992; Fusegawa et al., 1999; Hung et al., 1995; Lupia et al., 2010). Evaluation of platelet activity after tobacco use or after intravenous infusion of nicotine may however reflect endothelial dependent effects on platelet function. Both smoking and nicotine can cause endothelial dysfunction and subsequently reduced nitric oxide availability (Chalon et al., 2000; Mayhan \& Patel 1997; Neunteufl et al., 2002), which may result in increased platelet activity. In addition, the synthesis of $\mathrm{TXA}_{2}$ by COX-2 is increased in smokers, which probably is the result of COX-2 activity in inflammatory cells (McAdam et al., 2005). Nonetheless, it is probable that cigarette smoking also does act in more direct ways to affect platelet function. A recent study showed upregulation of adhesive proteins (platelet glycoprotein IIb, beta-actin and Factor XIII-A subunit) on platelets from smokers as compared with non-smokers, whereas platelet function was similar (Della Corte et al., 2011).

Taken together, the direct effect of tobacco and/or nicotine on platelet activity is difficult to elucidate from in vivo studies, since platelets can be affected in several indirect ways. Most previous studies investigate the effect of either smoking or intravenous infusion of nicotine, where nicotine has been subjected to metabolism. The results from those studies may represent the sum of both nicotine and nicotine metabolite mediated responses. However, the present study allowed us to distinguish the effects of nicotine and the different metabolites per se. Our study examining direct effect of tobacco on platelets showed that treatment with tobacco extract in vitro inhibits platelet adhesion to protein surfaces. As only a limited effect of nicotine and nicotine metabolites were seen, this effect is likely due to other platelet inhibitors present in tobacco. This effect could be mediated by for example phenolic compounds or some unknown and untested component present in various plants since platelet inhibition was observed also with tobacco free snuff. The effects could also be a complex mechanism of additive and synergistic action by several of the many compounds present in tobacco and other plants. 


\section{FUNDING}

This study was supported with grants from the Swedish Research Council, Cardiovascular Inflammatory Research Centre (CIRC, Linköping University, Sweden), Hälsofonden (Linköping, Sweden), County Council of Östergötland (Linköping, Sweden), Eleanora Demeroutis Foundation for Cardiovascular Research (Linköping, Sweden) and The Medical Advisory Council (Swedish Match Northern Europe AB).

\section{DECLARATION OF INTEREST}

The authors declare no conflicts of interest.

\section{ACKNOWLEDGEMENTS}

The authors thank Sven and Gullan Persson, Sandbergs Cigarraffär (Ystad, Sweden) for supplying us with cigarettes, Swedish Match (Stockholm, Sweden) for the oral snuff, Nicofree AB (Trångsviken, Sweden) for the tobacco free snuff, and Jenny Nilsson for performing some of the experiments. 


\section{REFERENCES}

Barua, R.S., Sy, F., Srikanth, S., Huang, G., Javed, U., Buhari, C., Margosan, D., Ambrose, J.A. (2010). Effects of cigarette smoke exposure on clot dynamics and fibrin structure: an ex vivo investigation. Arterioscler Thromb Vasc Biol 30, 75-79.

Becker, B.F., Terres, W., Kratzer, M., Gerlach, E. (1988). Blood platelet function after chronic treatment of rats and guinea pigs with nicotine. Klin Wochenschr 66 Suppl 11, 28-36.

Benowitz, N.L. (1996). Pharmacology of nicotine: addiction and therapeutics. Annu Rev Pharmacol Toxicol 36, 597-613.

Benowitz, N.L., Gourlay, S.G. (1997). Cardiovascular toxicity of nicotine: implications for nicotine replacement therapy. J Am Coll Cardiol 29, 1422-1431.

Benowitz, N.L., Jacob, P., 3rd (1994). Metabolism of nicotine to cotinine studied by a dual stable isotope method. Clin Pharmacol Ther 56, 483-493.

Benowitz, N.L., Jacob, P., 3rd (2001). Trans-3'-hydroxycotinine: disposition kinetics, effects and plasma levels during cigarette smoking. Br J Clin Pharmacol 51, 53-59.

Benowitz, N.L., Jacob, P., 3rd, Fong, I., Gupta, S. (1994). Nicotine metabolic profile in man: comparison of cigarette smoking and transdermal nicotine. J Pharmacol Exp Ther 268, 296-303.

Brockmann, M.A., Beythien, C., Magens, M.M., Wilckens, V., Kuehnl, P., Gutensohn, K. (2001). Platelet hemostasis capacity in smokers. In vitro function analyses with $3.2 \%$ citrated whole blood. Thromb Res 104, 333-342.

Chalon, S., Moreno, H., Jr., Benowitz, N.L., Hoffman, B.B., Blaschke, T.F. (2000). Nicotine impairs endothelium-dependent dilatation in human veins in vivo. Clin Pharmacol Ther 67, 391-397.

Chlopicki, S., Olszanecki, R., Marcinkiewicz, E., Lomnicka, M., Motterlini, R. (2006). Carbon monoxide released by CORM-3 inhibits human platelets by a mechanism independent of soluble guanylate cyclase. Cardiovasc Res 71, 393-401.

Cluette-Brown, J., Mulligan, J., Doyle, K., Hagan, S., Osmolski, T., Hojnacki, J. (1986). Oral nicotine induces an atherogenic lipoprotein profile. Proc Soc Exp Biol Med 182, 409413.

Crooks, P.A., Dwoskin, L.P. (1997). Contribution of CNS nicotine metabolites to the neuropharmacological effects of nicotine and tobacco smoking. Biochem Pharmacol 54, 743-753.

Davis, J.W., Arnold, J. (1992). Time course of some effects of cigarette smoking on platelets. J Intern Med 231, 31-36.

de Gasparo, M., Catt, K.J., Inagami, T., Wright, J.W., Unger, T. (2000). International union of pharmacology. XXIII. The angiotensin II receptors. Pharmacol Rev 52, 415-472.

Della Corte, A., Tamburrelli, C., Crescente, M., Giordano, L., D'Imperio, M., Di Michele, M., Donati, M.B., De Gaetano, G., Rotilio, D., Cerletti, C. (2011). Platelet proteome in healthy volunteers who smoke. Platelets 23, 91-105.

Eriksson, A.C., Whiss, P.A. (2005). Measurement of adhesion of human platelets in plasma to protein surfaces in microplates. J Pharmacol Toxicol Methods 52, 356-365.

Eriksson, A.C., Whiss, P.A. (2009). Characterization of static adhesion of human platelets in plasma to protein surfaces in microplates. Blood Coagul Fibrinolysis 20, 197-206.

Fusegawa, Y., Goto, S., Handa, S., Kawada, T., Ando, Y. (1999). Platelet spontaneous aggregation in platelet-rich plasma is increased in habitual smokers. Thromb Res 93, 271-278.

Gahring, L.C., Rogers, S.W. (2005). Neuronal nicotinic acetylcholine receptor expression and function on nonneuronal cells. AAPS J 7, E885-894. 
Gryglewski, R.J., Korbut, R., Robak, J., Swies, J. (1987). On the mechanism of antithrombotic action of flavonoids. Biochem Pharmacol 36, 317-322.

Hergens, M.P., Alfredsson, L., Bolinder, G., Lambe, M., Pershagen, G., Ye, W. (2007). Longterm use of Swedish moist snuff and the risk of myocardial infarction amongst men. $\mathbf{J}$ Intern Med 262, 351-359.

Hung, J., Lam, J.Y., Lacoste, L., Letchacovski, G. (1995). Cigarette smoking acutely increases platelet thrombus formation in patients with coronary artery disease taking aspirin. Circulation 92, 2432-2436.

Kahkonen, M.P., Hopia, A.I., Vuorela, H.J., Rauha, J.P., Pihlaja, K., Kujala, T.S., Heinonen, M. (1999). Antioxidant activity of plant extracts containing phenolic compounds. J Agric Food Chem 47, 3954-3962.

Ljungberg, L.U., Persson, K. (2008). Effect of nicotine and nicotine metabolites on Angiotensin-converting enzyme in human endothelial cells. Endothelium 15, 239-245.

Lupia, E., Bosco, O., Goffi, A., Poletto, C., Locatelli, S., Spatola, T., Cuccurullo, A., Montrucchio, G. (2010). Thrombopoietin contributes to enhanced platelet activation in cigarette smokers. Atherosclerosis 210, 314-319.

Mayhan, W.G., Patel, K.P. (1997). Effect of nicotine on endothelium-dependent arteriolar dilatation in vivo. Am J Physiol 272, H2337-2342.

McAdam, B.F., Byrne, D., Morrow, J.D., Oates, J.A. (2005). Contribution of cyclooxygenase2 to elevated biosynthesis of thromboxane A2 and prostacyclin in cigarette smokers. Circulation 112, 1024-1029.

McGrath, T., Brown, A., Meruva, N., Chan, W. (2009). Phenolic compound formation from the low temperature pyrolysis of tobacco. J Anal Appl Pyrol 84, 170-178.

Nair, S., Kulkarni, S., Camoens, H.M., Ghosh, K., Mohanty, D. (2001). Changes in platelet glycoprotein receptors after smoking--a flow cytometric study. Platelets 12, 20-26.

Neunteufl, T., Heher, S., Kostner, K., Mitulovic, G., Lehr, S., Khoschsorur, G., Schmid, R.W., Maurer, G., Stefenelli, T. (2002). Contribution of nicotine to acute endothelial dysfunction in long-term smokers. J Am Coll Cardiol 39, 251-256.

Nowak, J., Andersson, K., Benthin, G., Chen, J., Karlberg, K.E., Sylven, C. (1996). Effect of nicotine infusion in humans on platelet aggregation and urinary excretion of a major thromboxane metabolite. Acta Physiol Scand 157, 101-107.

Perfetti, T., Rodgman, A. (2008). The Chemical Components of Tobacco and Tobacco Smoke. [CRC Press]. doi:10.1201/9781420078848.fmatt

Persson, K., Whiss, P.A., Nyhlen, K., Jacobsson-Strier, M., Glindell, M., Andersson, R.G. (2000). Nitric oxide donors and angiotensin-converting enzyme inhibitors act in concert to inhibit human angiotensin-converting enzyme activity and platelet aggregation in vitro. Eur J Pharmacol 406, 15-23.

Petro, T.M., Anderson, L.L., Gowler, J.S., Liu, X.J., Schwartzbach, S.D. (2002). Smokeless tobacco extract decreases IL-12 production from LPS-stimulated but increases IL-12 from IFN-gamma-stimulated macrophages. Int Immunopharmacol 2, 345-355.

Pfueller, S.L., Burns, P., Mak, K., Firkin, B.G. (1988). Effects of nicotine on platelet function. Haemostasis 18, 163-169.

Pignatelli, P., Di Santo, S., Carnevale, R., Violi, F. (2005). The polyphenols quercetin and catechin synergize in inhibiting platelet CD40L expression. Thromb Haemost 94, 888889.

Renaud, S., Blache, D., Dumont, E., Thevenon, C., Wissendanger, T. (1984). Platelet function after cigarette smoking in relation to nicotine and carbon monoxide. Clin Pharmacol Ther 36, 389-395. 
Riveles, K., Roza, R., Talbot, P. (2005). Phenols, quinolines, indoles, benzene, and 2cyclopenten-1-ones are oviductal toxicants in cigarette smoke. Toxicol Sci 86, 141151.

Rubenstein, D., Jesty, J., Bluestein, D. (2004). Differences between mainstream and sidestream cigarette smoke extracts and nicotine in the activation of platelets under static and flow conditions. Circulation 109, 78-83.

Schedel, A., Thornton, S., Schloss, P., Kluter, H., Bugert, P. (2011). Human platelets express functional alpha7-nicotinic acetylcholine receptors. Arterioscler Thromb Vasc Biol 31, 928-934.

Shanker, G., Kontos, J.L., Eckman, D.M., Wesley-Farrington, D., Sane, D.C. (2006). Nicotine upregulates the expression of P2Y12 on vascular cells and megakaryoblasts. J Thromb Thrombolysis 22, 213-220.

Strohschneider, T., Oberhoff, M., Hanke, H., Hannekum, A., Karsch, K.R. (1994). Effect of chronic nicotine delivery on the proliferation rate of endothelial and smooth muscle cells in experimentally induced vascular wall plaques. Clin Investig 72, 908-912.

Su, Y., Han, W., Giraldo, C., De Li, Y., Block, E.R. (1998). Effect of cigarette smoke extract on nitric oxide synthase in pulmonary artery endothelial cells. Am J Respir Cell Mol Biol 19, 819-825.

Toivanen, J., Ylikorkala, O., Viinikka, L. (1986). Effects of smoking and nicotine on human prostacyclin and thromboxane production in vivo and in vitro. Toxicol Appl Pharmacol 82, 301-306.

Vainio, P.J., Tornquist, K., Tuominen, R.K. (2000). Cotinine and nicotine inhibit each other's calcium responses in bovine chromaffin cells. Toxicol Appl Pharmacol 163, 183-187.

Wennmalm, A., Benthin, G., Granstrom, E.F., Persson, L., Petersson, A.S., Winell, S. (1991). Relation between tobacco use and urinary excretion of thromboxane A2 and prostacyclin metabolites in young men. Circulation 83, 1698-1704.

Whiss, P.A., Andersson, R.G., Srinivas, U. (1997). Modulation of P-selectin expression on isolated human platelets by an NO donor assessed by a novel ELISA application. J Immunol Methods 200, 135-143.

Whiss, P.A., Lundahl, T.H., Bengtsson, T., Lindahl, T.L., Lunell, E., Larsson, R. (2000). Acute effects of nicotine infusion on platelets in nicotine users with normal and impaired renal function. Toxicol Appl Pharmacol 163, 95-104.

Wright, B., Moraes, L.A., Kemp, C.F., Mullen, W., Crozier, A., Lovegrove, J.A., Gibbins, J.M. (2010). A structural basis for the inhibition of collagen-stimulated platelet function by quercetin and structurally related flavonoids. Br J Pharmacol 159, 13121325 . 


\section{FIGURE LEGENDS}

FIGURE1. Effects of various concentrations of nicotine $(\bullet)$, cotinine $(\boldsymbol{\square})$, cotinine-N-oxide $(\boldsymbol{\Delta})$, nicotine-1'-N-oxide $(\boldsymbol{\nabla})$ and trans-3'-hydroxycotinine $(\boldsymbol{})$ on platelet aggregation induced by $10 \mu \mathrm{M}$ adenosine 5-diphosphate (ADP). Data are mean \pm SEM, $\mathrm{n}=6$ independent experiments performed in duplicates. Statistical significance is described with $* p<0.05$ compared with solvent.

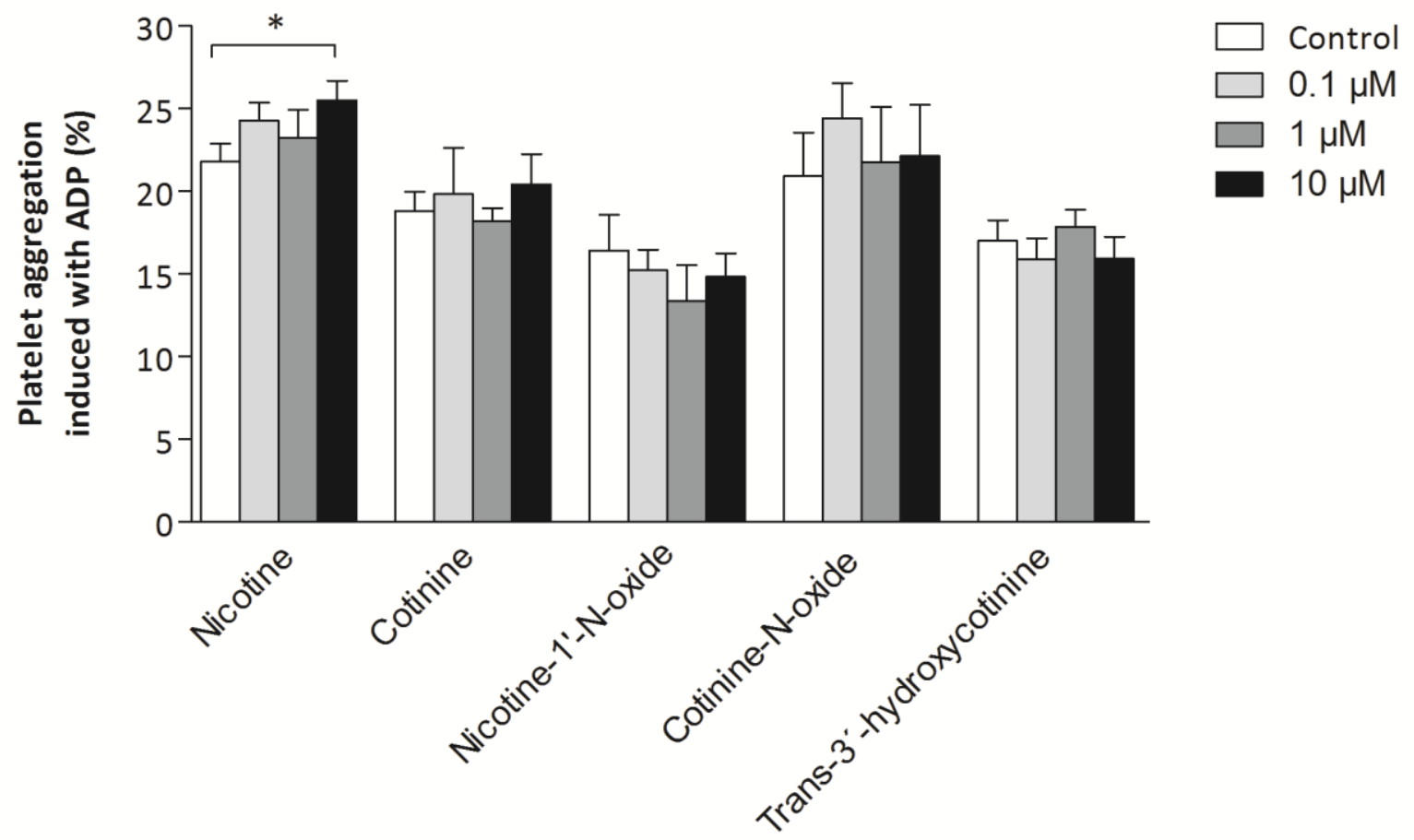


FIGURE 2. Platelet adhesion to collagen $(\boldsymbol{\Delta})$, fibrinogen $(\nabla)$ and albumin $(\boldsymbol{\nabla})$ after treatment with A) nicotine, B) cotinine, C) trans-3'-hydroxycotinine, D) nicotine-1'-N-oxide, and E) cotinine-N-oxide 0.1-10 $\mu \mathrm{M}$. Data are mean $\pm \mathrm{SEM}, \mathrm{n}=6-10$ independent experiments performed in duplicates. Statistical significance is described with $* p<0.05$, ** $p<0.01$ compared with solvent.
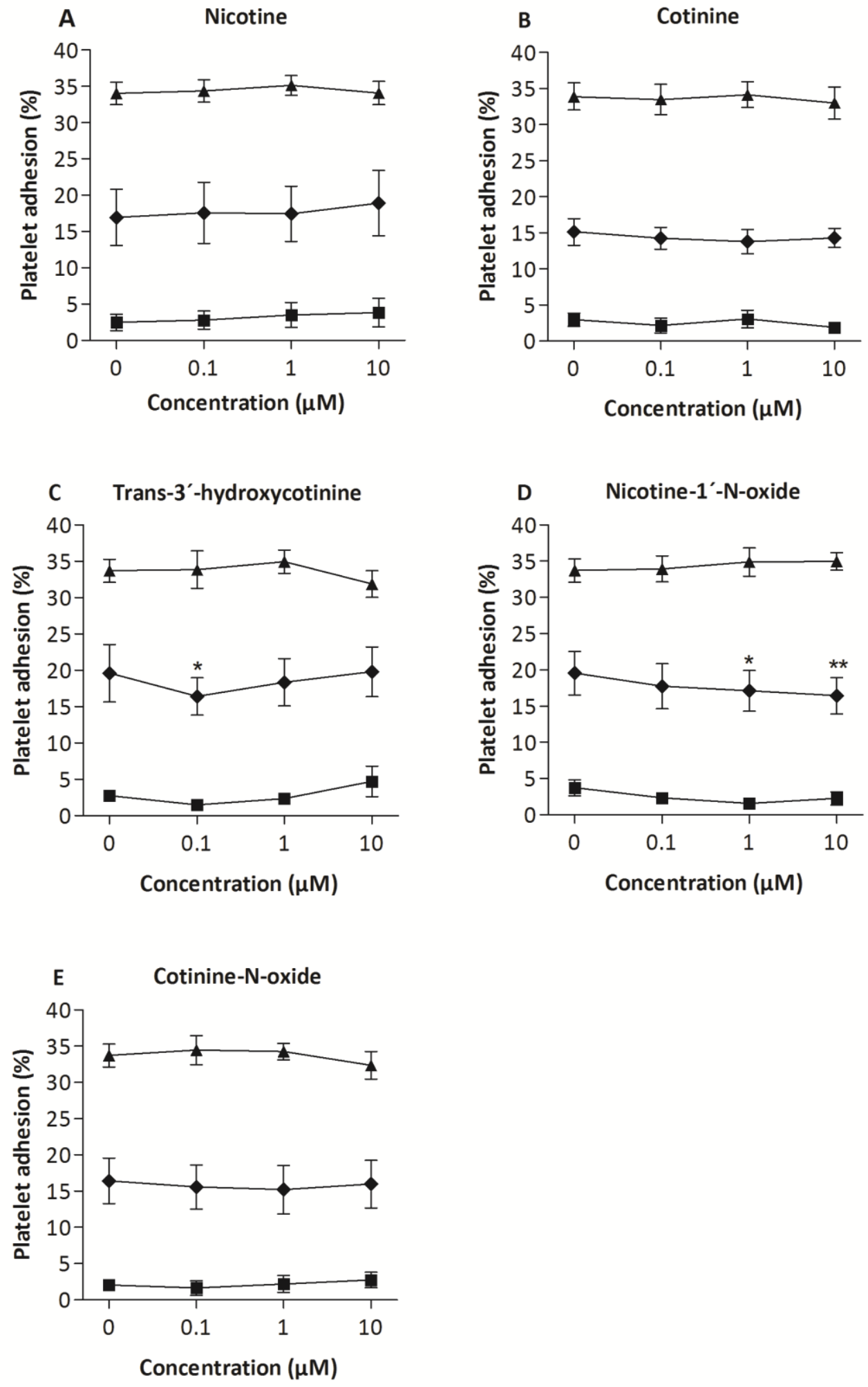
FIGURE 3. Platelet adhesion to collagen ( $\boldsymbol{\Delta})$, fibrinogen $(\boldsymbol{\nabla})$ and albumin $(\boldsymbol{\square})$ after treatment with extract of A) Ettan moist, B) Copenhagen moist, C) Camel cigarette smoke and D)

Choice apple. An extract concentration of $100 \%$ corresponds to a filtered solution containing $0.1 \mathrm{~g}$ Ettan, Copenhagen or Choice apple /ml PBS, while 100\% Camel extracts corresponds to 2 cigarettes $/ 10 \mathrm{ml}$ PBS. Data are mean $\pm \mathrm{SEM}, \mathrm{n}=6$ independent experiments performed in duplicates. Statistical significance is described with $* p<0.05$, ** $p<0.01 * * * p<0.001$ for collagen, \# $\mathrm{p}<0.05$, \#\# $\mathrm{p}<0.01$, \#\#\# $\mathrm{p}<0.001$ for fibrinogen, and $\S \S \S \mathrm{p}<0.01$ for albumin compared with solvent.
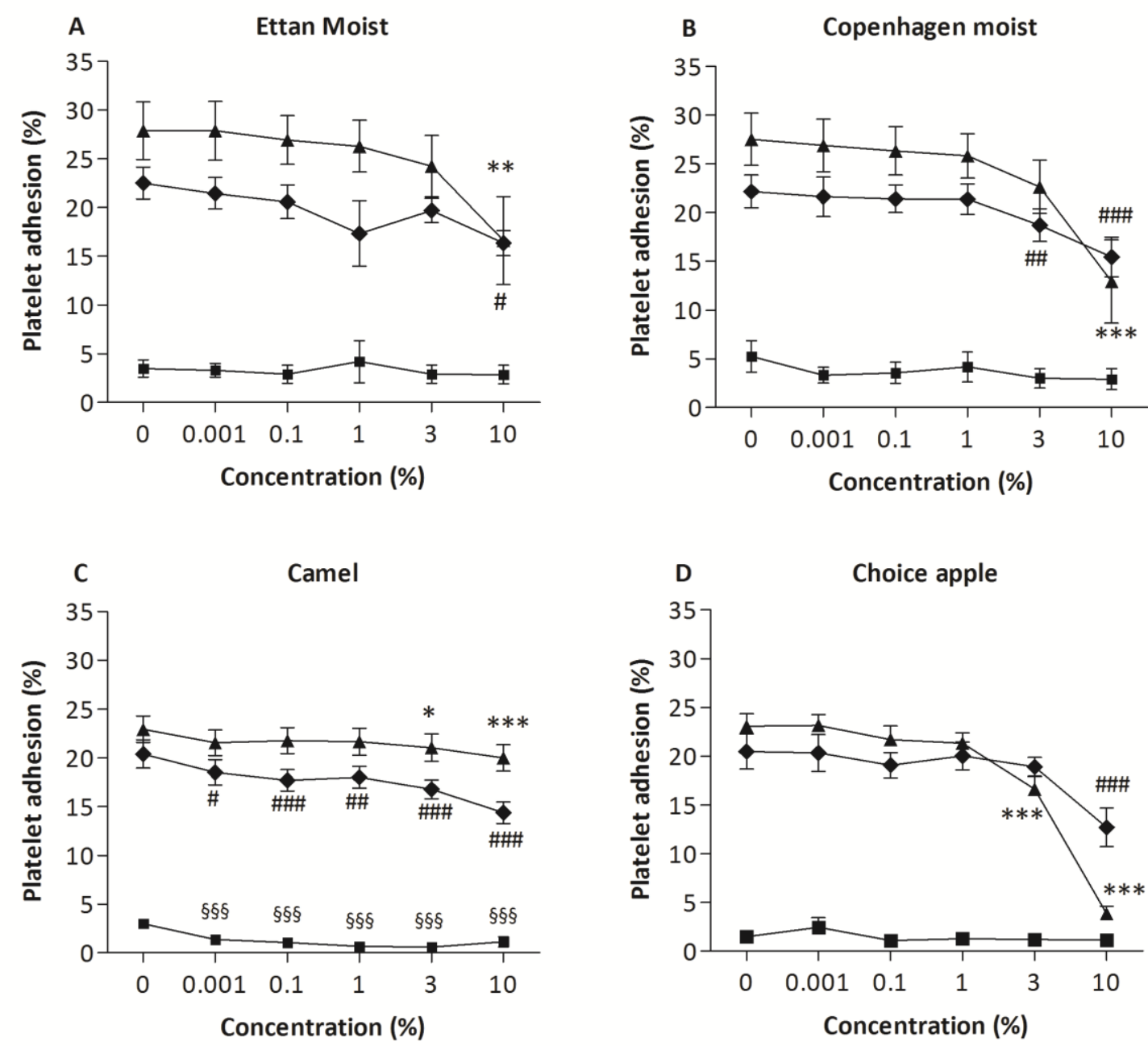
FIGURE 4. Effect of extract of A) Ettan moist, and B) Camel cigarette smoke, on platelet adhesion to albumin after co-incubation with ADP $1 \mu \mathrm{M}$ and adrenaline $1 \mu \mathrm{M}$. An extract concentration of $100 \%$ corresponds to a filtered solution containing $0.1 \mathrm{~g}$ Ettan, Copenhagen or Choice apple /ml PBS, while 100\% Camel extracts corresponds to 2 cigarettes/10 ml PBS. Data are mean \pm SEM, $n=3$ independent experiments performed in duplicates. Statistical significance is described with $* \mathrm{p}<0.05, * * \mathrm{p}<0.01$, and $* * * \mathrm{p}<0.001$ compared with solvent.

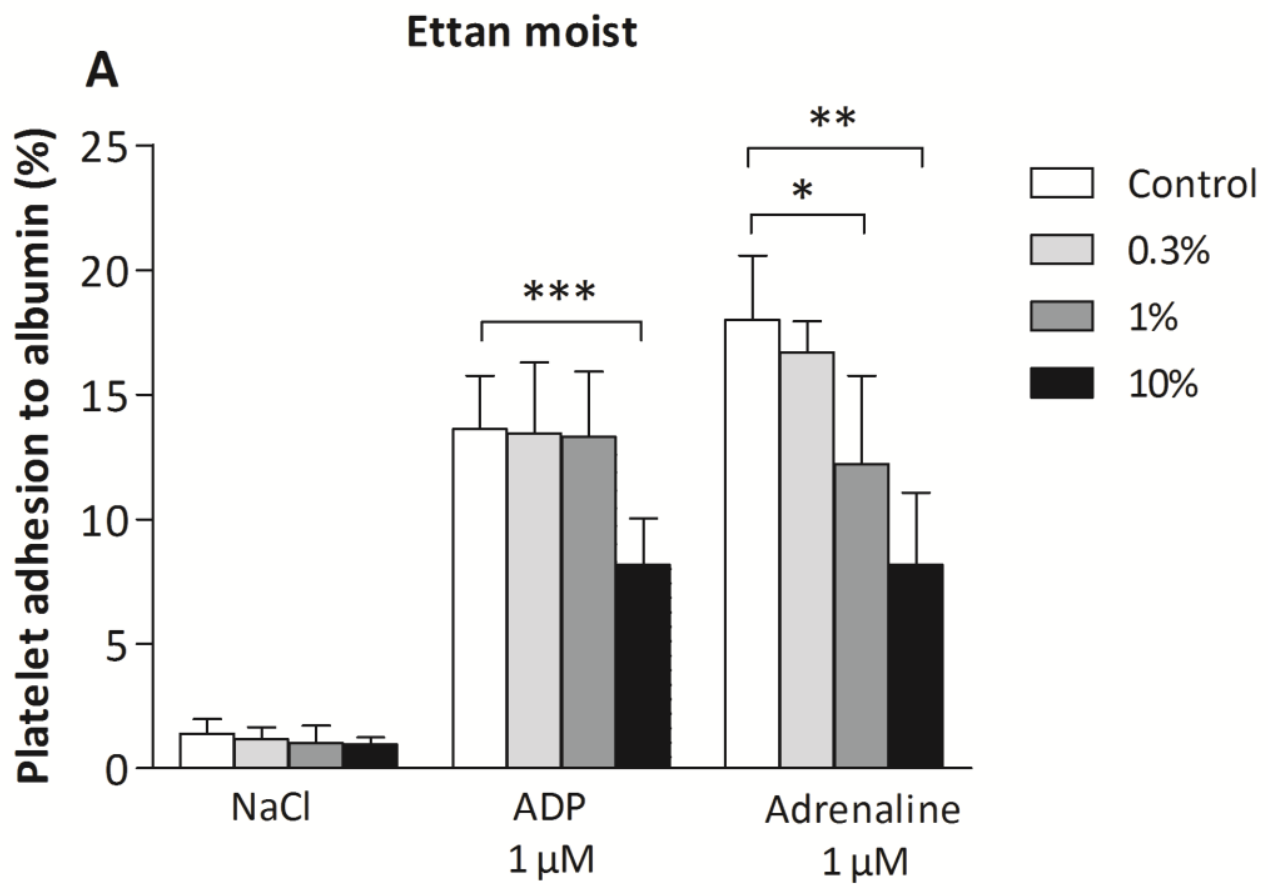

B

Camel

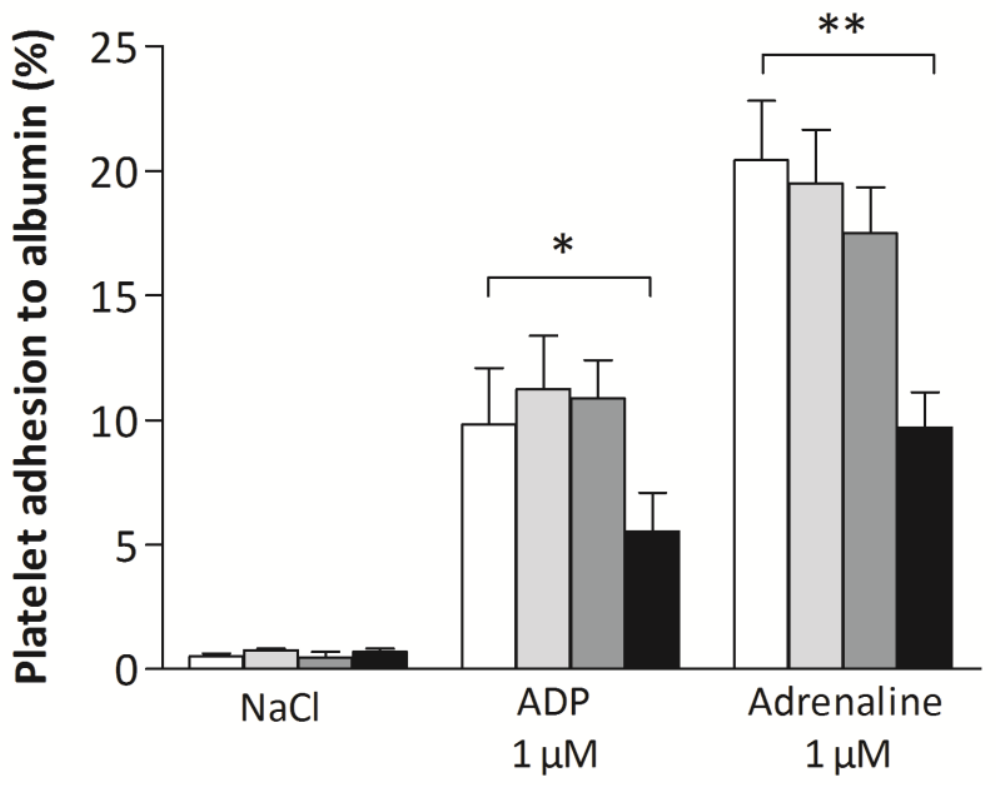



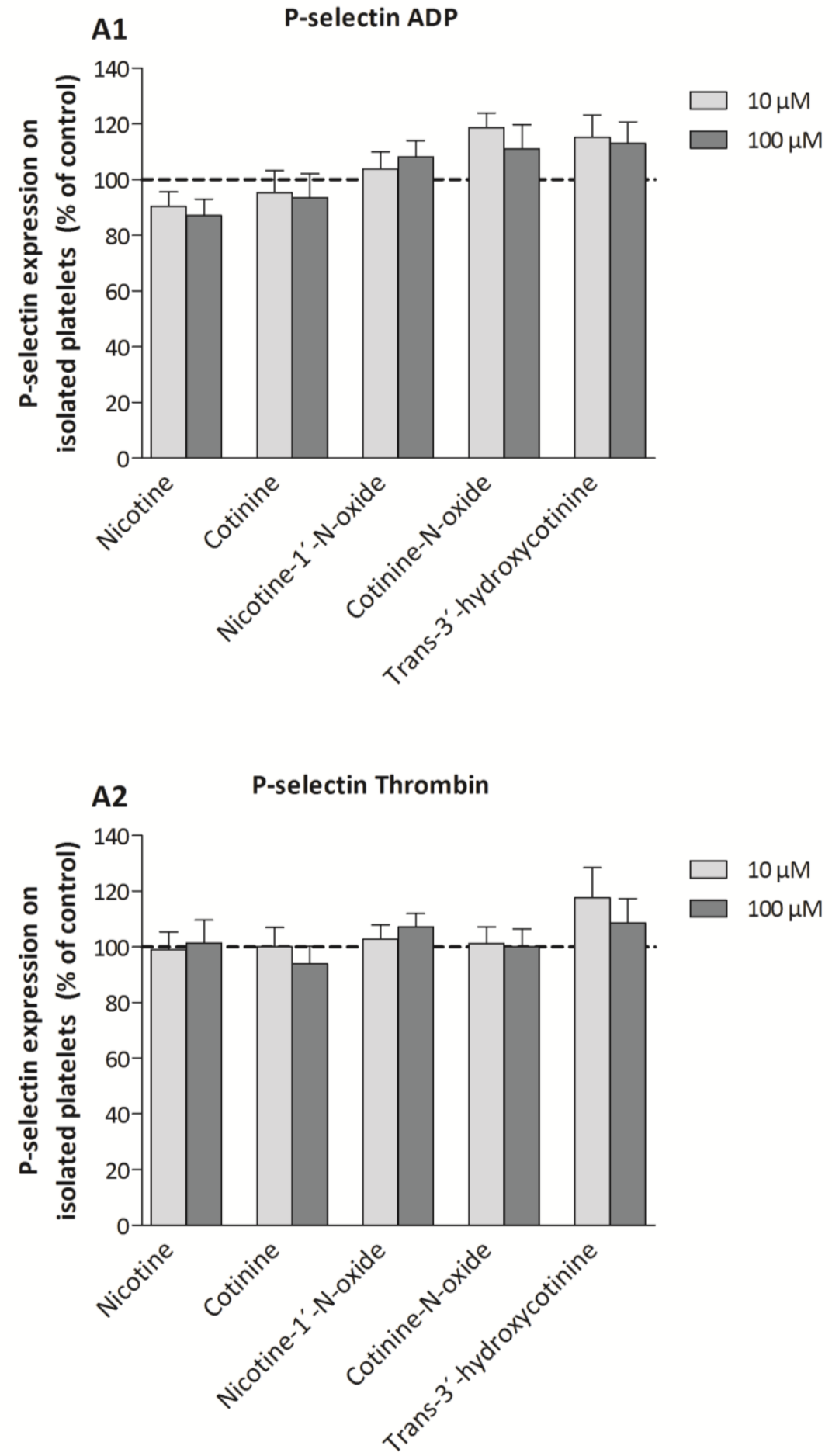

APPENDIX A. Effects of nicotine, cotinine, cotinine-N-oxide, nicotine-1'-N-oxide and trans3'-hydroxycotinine (10 and $100 \mu \mathrm{M}$ ) on platelet P-selectin expression induced by A1) $10 \mu \mathrm{M}$ adenosine 5-diphosphate (ADP) or A2) $0.1 \mathrm{U} / \mathrm{ml}$ thrombin. Data are the mean $\pm \mathrm{SEM}, \mathrm{n}=6$ independent experiments performed in duplicates. None of the compounds caused any significant difference as compared with solvent. 

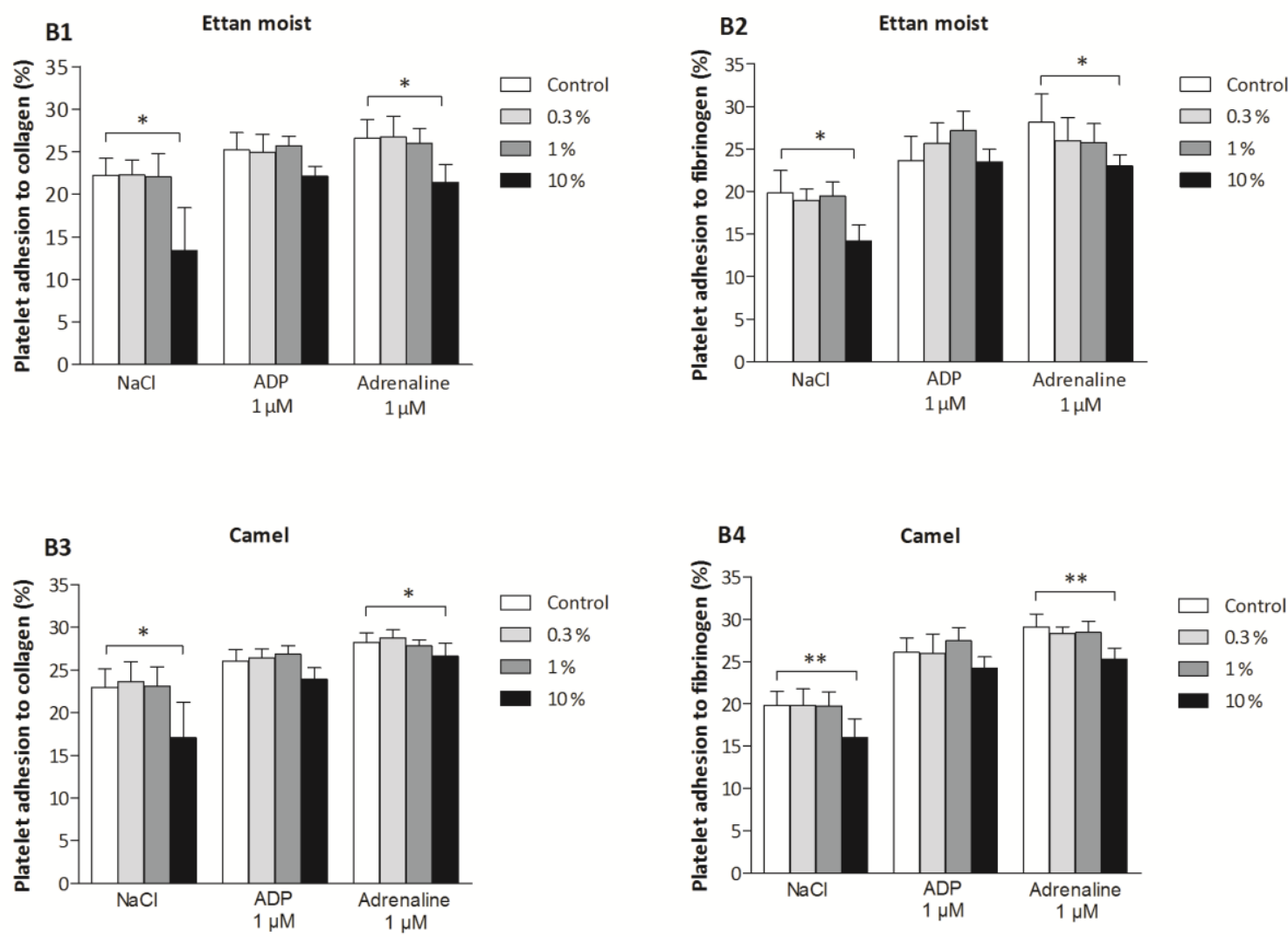

APPENDIX B. Effect of extract of B1-B2) Ettan moist, and B3-B4) Camel cigarette smoke, on platelet adhesion to collagen and fibrinogen after co-incubation with ADP $1 \mu \mathrm{M}$ and adrenaline $1 \mu \mathrm{M}$. An extract concentration of $100 \%$ corresponds to a filtered solution containing $0.1 \mathrm{~g}$ Ettan, Copenhagen or Choice apple /ml PBS, while 100\% Camel extracts corresponds to 2 cigarettes $/ 10 \mathrm{ml}$ PBS. Data are mean \pm SEM, $n=3$ independent experiments performed in duplicates. Statistical significance is described with $* \mathrm{p}<0.05$ and $* * \mathrm{p}<0.01$ compared with solvent. 
SUPPLEMENTARY FIGURE C

\section{Ingredients list}

\section{Ettan moist}

Ingredients added to the tobacco

Water

Sodium chloride

Propylene glycol

Glycerol

Sodium carbonate

Flavours

http://www.swedishmatch.com/en/Our-business/Snus-and-snuff/Ingredients-in-snus/?tab=0

\section{Copenhagen}

Ingredients added to the tobacco

Water

Sodium Chloride

Ethyl Alcohol

Sodium Carbonate

Ammonium Carbonate

Preservatives

Flavours

http://www.ussmokeless.com/en/cms/Products/Ingredients_Nav/Ingredients/Ingredients_by_Brand/Copenhagen/Copenhagen _Snuff_Fine_Cut.aspx

\section{Camel cigarettes}

Ingredients added to the tobacco

Water

Glycerol

Brown Sugar

Propylene Glycol

High Fructose Corn Syrup

Sucrose

Cellulose Fibre

Cocoa

Liquorice

Diammonium Phosphate

Ammonium Hydroxide

Flavours

http://www.rjrt.com/brandcompounds.aspx

\section{Choice Apple}

Herbs

Spices

Flavours

http://www.nicofree.se/index.asp?!=35 